\title{
The Journal of Headache and Pain keeps gaining consensus
}

\author{
Paolo Martelletti
}

Published online: 22 July 2010

(C) Springer-Verlag 2010

As soon as confusion following the release of 2009 IF had ceased, a regular JHP reader could realise in the first place that this project passed a test of courage and swiftness, along with the fact that it was not madness which paid us a visit 10 years ago [1]. Relentless competition aimed at overcoming self-imposed limits has always represented a recipe for success. Now, the risk for JHP is to linger in idleness, in a creeping sense of lethargy.

Once again, I would like to share with the readers the most recent accomplishments of JHP [2]. We all can be proud of the work expressed during the last year, without exception: Board members, reviewers and authors. A warm Thank You also goes to the European Headache Federation (EHF) for its active institutional participation to the scientific life of JHP.

\section{Impact factor}

Thomson-Reuters has recently published the IF list for 2009. JHP's growth is steady and its new IF reached 2.137. At present, JHP's rank is 86/167 in the Clinical Neurology category and $154 / 230$ in the Neuroscience category. Besides, self-citation for JHP during the years considered in IF calculation is quite low (11\%). For further details, information is available in the ESM of this article.

Electronic supplementary material The online version of this article (doi:10.1007/s10194-010-0246-8) contains supplementary material, which is available to authorized users.

P. Martelletti $(\square)$

Department of Medical and Molecular Sciences,

II School of Medicine, Sapienza University of Rome,

Rome, Italy

e-mail: Paolo.Martelletti@uniroma1.it

\section{Affiliation with Lifting The Burden}

A new partnership between Lifting The Burden-The Global Campaign against Headache (LTB-GC) and JHP has come to life, through the designation of JHP as official journal of LTB, as well as of EHF. This newborn liaison relies on GC's strategic importance as well as in the complementary missions of both EHF and LTB.

\section{Boards}

A decisive remodelling of both the Editorial and the Advisory Board has been carried out, in line with the abovementioned conditions as well as with active participation to editorial processes. The new Co-Editor on behalf of LTB, Lars J. Stovner, will team up with Rigmor Jensen, Co-Editor on behalf of EHF. We welcome the new Associate Editor, Timothy J. Steiner. In the Advisory Board, noteworthy names have been included. Their renowned scientific activity in favour of JHP will synergize well with the work of earlier members. A special Thank You goes to all those who are leaving the Boards, for everything they could do and for how everyone believed in JHP's growth project.

\section{SpringerOpen}

The future of science publishing is irrevocably oriented towards complete free access to journal contents. The purpose is the free circulation of ideas as well as their rapid application and inclusion into a virtuous channel of both cultural and economical production.

Springer welcomed this new challenge and will publish open access journals under the umbrella name of 
SpringerOpen (www.springeropen.com). Together with other journals, JHP has been chosen to pioneer such project. All articles will be freely and permanently available on line in pdf and HTML format, Authors will retain copyright under the liberal Creative Commons Attribution license that allows for re-use. Such innovation will certainly maximize the visibility of the journal, and thus the uptake and use of articles contributing to a sharp increase of citations. All articles will be subjected to rigorous peerreview; online submission systems and efficient production technology will allow rapid publication times.

Publication costs will be covered through unconditioned multiple sponsorship to JHP; industry will levy article processing charges enabling all the research in the journal made freely available without any financial support from the authors.

\section{Final remarks}

Looking back at JHP's last decade, it appears clearly that several names contributed to headache science with innovative interpretations. Some of them came into view early in their career, others are fixed in memory like paradigms, representing a challenging yardstick for younger researchers. JHP never hazarded statements such as "giant among giants" or "cradle of science" in reference to its own history. Nevertheless, data concerning comparative IF indicate that JHP is approaching field journals which have been important all along.

\section{References}

1. Martelletti P (2009) While climbing the hill, you think it's possible. J Headache Pain 10:309-310

2. Martelletti P (2009) New policies to consolidate the journal's hold on its latest position. J Headache Pain 10:1-2 